\title{
Alvenaria estrutural na construção civil
}

\author{
Structural masonry in civil construction
}

\author{
Beatriz da Rocha Pereira Menezes"; Luiz Antonio Mendes de Avellar Junior**; Tatiana Ignácio Diniz ; \\ Diego Henriques Motta Eiras ${ }^{\ddagger}$ Gustavo José da Costa Gomes`; Cleber José Fermiano Paschoal ${ }^{\S}$
}

Como citar esse artigo. Menezes, BRP; Junior, LAMA; Diniz, TI; Eiras, DHM; Gomes, GJC; Paschoal, CJF. Alvenaria estrutural na construção civil. Revista Teccen. 2018 Jul./Dez.; 11 (2): 16-22.

\begin{abstract}
Resumo
A alvenaria estrutural é uma tecnologia construtiva tradicional que vem sendo utilizada há milhares de anos, tendo apresentado nas últimas décadas, grandes e visíveis avanços, tornando-se um processo construtivo racionalizado com normas técnicas consistentes e específicas. Torna-se uma solução bastante viável para o grande déficit habitacional do Brasil, uma vez que é mais rápida, racional e barata, quando comparada com a construção tradicional. O presente artigo tem como foco pesquisar o processo de execução da Alvenaria Estrutural visando demonstrar que a mesma, por ser um sistema construtivo que adota os princípios de racionalização, industrialização, qualidade e economia, é bastante adequada para a realidade brasileira. Para tanto, é realizada uma pesquisa bibliográfica com abordagem qualitativa incluindo obras utilizando este tipo de alvenaria, sendo criteriosamente analisadas e selecionadas. Também são apresentadas fotos de acompanhamento de uma obra utilizando-se alvenaria estrutural, para exemplificação da simplicidade de execução. Como resultado final é verificado que a alvenaria estrutural proporciona uma economia real de dinheiro e de tempo no processo construtivo.

Palavras-Chave: alvenaria estrutural; construção civil; elementos de vedação.
\end{abstract}

\begin{abstract}
Structural masonry is a traditional constructional technology that has been used for thousands of years and has shown great and visible advances in the last decades, becoming a rationalized constructive process with consistent and specific technical norms. It is a very viable solution to the large housing deficit in Brazil, since it is faster, more rational and cheaper compared to traditional construction. The present article focuses on the structural masonry execution process in order to demonstrate that it is a constructive system that adopts the principles of rationalization, industrialization, quality and economy, and is quite adequate for the Brazilian reality. For this, a bibliographical research with a qualitative approach is carried out, including works using this type of masonry, being carefully analyzed and selected. Also accompanying photos of a work are presented using structural masonry, to exemplify the simplicity of execution. As a final result it is verified that the structural masonry provides a real saving of money and time in the constructive process..

Keywords: structural masonry; construction; sealing elements.
\end{abstract}

\section{Introdução}

A alvenaria estrutural é conceituada como um sistema construtivo que se caracteriza pelo emprego de paredes de alvenaria e lajes enrijecidas que atuam como principal estrutura de suporte das edificações (CAVALHEIRO, 2009). Trata-se de um sistema construtivo que possibilita uma grande racionalização e maior produtividade se comparada com os sistemas convencionais. Em uma construção, tais fatores se revertem em economia e maior lucro. Para tanto, alguns cuidados devem ser tomados como projetos específicos para o sistema, planejamento do empreendimento, mão de obra especializada, materiais de qualidade e controle de produção da obra (RAMALHO \& CORRÊA, 2003). A alvenaria estrutural destaca-se devido à grande redução dos custos da construção, juntamente com a grande agilidade e racionalidade do sistema, sendo uma solução bastante viável para o grande déficit habitacional do Brasil. Por esse motivo, vem ao longo dos anos se desenvolvendo e atingindo o mercado de obras de médio e alto padrão, dominando empreendimentos horizontais e verticais em todo o país (CÔELHO, 1998).

À vista disto, ela não deve ser vista meramente como um conjunto de paredes superpostas, resistindo o seu peso próprio e outras cargas adicionais. Deve ser compreendida como sendo um processo construtivo racionalizado, projetado, calculado e construído em

\footnotetext{
†Graduada em Engenharia Civil pelo Centro Universitário Geraldo Di Biase, Barra do Piraí, Rio de Janeiro, Brasil;

* Graduando em Engenharia Civil pela Universidade de Vassouras, Vassouras, Rio de Janeiro, Brasil

$\S$ Docente no curso de Engenharia Civil na Universidade de Vassouras, Vassouras, Rio de Janeiro, Brasil

* Email para correspondência: avellarjr@bol.com.br 
conformidade com as normas pertinentes, visando funcionalidade com segurança e economia.

Dessa maneira, o presente artigo tem como objetivo apresentar o processo de execução da alvenaria estrutural, demonstrando seus princípios de racionalização, industrialização, qualidade e economia, os quais o tornam um sistema construtivo bastante adequado para a realidade brasileira. Para tanto, através de revisão de literatura, é realizado um levantamento bibliográfico incluindo obras utilizando este tipo de alvenaria, sendo criteriosamente analisadas e selecionadas. Também são apresentadas fotos da execução e acompanhamento de uma obra utilizando-se alvenaria estrutural, realizada na implantação de uma unidade de Pronto Atendimento da Prefeitura Municipal de Vassouras, para exemplificação da simplicidade de execução da obra.

\section{Referencial teórico}

Alvenaria Estrutural é o sistema construtivo no qual a estrutura da edificação é formada pelas próprias paredes, capazes de resistir a outras cargas além do seu peso próprio (PRUDÊNCIO JÚNIOR et al., 2002). Nesse sistema a execução é mais rápida por ser planejada. Os blocos, que podem ser de concreto, solo ou solocimento, melhoram os padrões construtivos, permitindo detalhamentos estéticos, além de proporcionarem um maior isolamento térmico, acústico e resistência ao fogo. $\mathrm{O}$ desenvolvimento deste processo construtivo surgiu através do empilhamento puro e simples de tijolos e blocos (RAMALHO \& CORRÊA, 2003). Foi projetada para resistir a esforços de compressão única ou ainda a uma combinação de esforços (ABCI, 1990), ligados entre si pela interposição de argamassa e podendo ainda conter armadura envolta em concreto ou argamassa no plano horizontal e/ou vertical.

Sabendo-se que a principal estrutura de suporte de um edifício é constituída por suas paredes, projetadas de acordo com modelos matemáticos preestabelecidos, a alvenaria estrutural torna-se um processo construtivo racionalizado onde os elementos que cumprem a função estrutural são de alvenaria, Ramalho \& Corrêa (2003). Onde o tipo de solicitação mais importante é a compressão, esforço que a alvenaria estrutural nãoarmada apresenta melhor resistência. Dessa maneira, devem ser evitadas tensões trações elevadas, para que o sistema se torne mais econômico.

Santos (2012) aponta como principais vantagens: economia e controle tecnológico; dimensões precisas; maior desempenho da mão de obra; menor consumo de argamassa de assentamento; uniformidade de textura; permite aplicação direta de revestimento sobre os blocos em paredes internas; embutimento de tubulações sem corte de alvenaria; menor índice de perda, diminuindo o entulho na obra; menor tempo de execução de obra.

Por ser um dos mais simples e eficientes métodos construtivos (COÊLHO, 1998), a alvenaria estrutural é um dos métodos mais utilizados em obras de construção civil na contemporaneidade. Principalmente por causa da racionalização construtiva do sistema, que possui uma projeção e dimensionamento bastante simplificados.

O que diferencia a alvenaria estrutural da alvenaria comum é que esta possui a função básica de vedação ou fechamento. Enquanto a alvenaria estrutural substitui dois principais sistemas de uma construção: a estrutura de concreto armado e os fechamentos de alvenaria (CAMPOS, 2012), onde as paredes da edificação são também a estrutura que suporta todas as cargas; o próprio peso, as lajes, coberturas e cargas adicionais, além de fatores externos, como por exemplo, o vento.

Ramalho e Corrêa (2003) apontam que a alvenaria estrutural, pode ser considerada como um sistema construtivo tradicional, uma vez que tem sido utilizada desde o início da atividade humana para diversos fins. Tendo surgindo com a necessidade de abrigo, proteção e conforto dos povos nômades. Pois com o passar do tempo, os materiais e as formas construtivas das habitações foram se aperfeiçoando (SILVA \& COSTA, 2007).

$\mathrm{Na}$ antiguidade, os egípcios, gregos e romanos, por exemplo, utilizavam pedra bruta encaixada como um quebra-cabeça na construção de fortalezas, igrejas e pirâmides. As primeiras alvenarias, em pedra ou em tijolo cerâmico seco ao sol, apresentavam grandes espessuras em suas obras mais imponentes (CAVALHEIRO, 2009). Exemplos clássicos desse tipo de construção são: o Farol de Alexandria no Mediterrâneo, o Templo de Efésio, o Coliseu de Roma, o Parthenon na Grécia (entre 480 e 323 a. C.) e a Muralha da China (entre 1368 e 1644). Esse tipo de construção predominou até o século XIX, quando surgiram as estruturas de aço e de concreto armado. Coelho (1998) aponta também a Torre de Babel, construída com tijolos queimados, e sobre casas edificadas com pedras preparadas nas pedreiras no ano de quatrocentos e oitenta a.C. Ramalho \& Corrêa (2003) citam também as Pirâmides de Guizé, localizadas no Egito, que necessitaram de inúmeras pessoas para sua execução utilizando blocos de pedra. A maior entre as três pirâmides é o túmulo do faraó Quéops, com 146 metros de altura e 230 metros de lado, juntamente com o Coliseu de Roma.

Com os novos ideais da Revolução Industrial, no século XVIII, houve grande incentivo à industrialização e à otimização dos processos construtivos. A partir daí a alvenaria estrutural começou a ser entendida como um sistema de fácil industrialização por permitir a padronização e modulação dos projetos, bem como a organização e limpeza do canteiro de obras, além de alta produtividade, qualidade e economia (SILVA \& COSTA, 2007). No auge do desenvolvimento da 
alvenaria estrutural, foi construído, entre 1889 e 1891, o Edifício Monadnock em Chicago (Figura 3), que possui 16 pavimentos de 65 metros de altura. Suas paredes têm base de 1,80 metros. RAMALHO \& CORREAA (2003) acreditam que utilizando-se o conhecimento da engenharia dos dias de hoje, suas paredes teriam, no máximo, uma espessura de $30 \mathrm{~cm}$.

Hirt \& Marangoni (2013) assinalam que foi somente na década de 1940 que os engenheiros e arquitetos começaram a estudar de maneira intensa a respeito das paredes portantes de alvenaria. Silva \& Costa (2007) também assinalam que apenas no final de 1940 que surgiram as normas para calcular a resistência das alvenarias e a espessura das paredes.

Foi elaborada na Inglaterra, em 1948, a primeira norma consistente de alvenaria estrutural; a CPIII "Structural recommendation for Load bearing Walls", que foi reformulada em 1970. Em 1970 também foi publicada a norma norte americana: "Specification for the Design" pela "National Concrete Masonry Association - NCMA" que influenciou de maneira marcante na evolução da Alvenaria Estrutural no Brasil. Os anos de 1960 e 1970 foram marcados por averiguações experimentais e melhoramento dos cálculos matemáticos, onde foram buscadas propostas resistentes às cargas estáticas e dinâmicas, assim como as ações de caráter excepcional como, por exemplo, explosões e retiradas de paredes estruturais (SILVA \& COSTA, 2007).

Cavalheiro (2009) aponta que atualmente, em vários países como Estados Unidos, Inglaterra e Alemanha a alvenaria estrutural dispõe níveis de cálculo, ação e controle, semelhantes aos colocados nas estruturas de aço e de concreto armado, se tornando um sistema econômico, flexível e de simples industrialização, em função das dimensões do bloco modular empregado.

No Brasil, é utilizada desde o início do século $\mathrm{XVI}$, quando os portugueses aqui chegaram, com o emprego de pedra, tijolo de barro cru e taipa de pilão (RAMALHO \& CORRÊA, 2003).

$\mathrm{Na}$ década de 1950 ocorreram as primeiras evoluções da técnica construtiva com o aproveitamento de tijolo de barro cozido, oportunizando construções mais robustas e com maiores vãos (CAVALHEIRO, 2009).

Ramalho e Corrêa (2003) assinalam que a primeira obra em alvenaria estrutural não armada foi fabricada no ano de 1977, em São Paulo (edifício Jardim Prudência executado em 9 pavimentos com paredes fortes de alvenaria em blocos sílico-calcários de 24 centímetros). Vários exemplos, após o advento da técnica de fabricação de blocos de concreto e normas de construção, são citados por Coêlho (1998), dentre eles um edifício em São José dos Campos, no interior de São Paulo, com 16 pavimentos realizados em alvenaria armada de blocos vazados de concreto de 19 centímetros de espessura.

Nos dias de hoje a Alvenaria Estrutural está tendo um grande impulso através de pesquisas onde se tem buscado o emprego de novos materiais. Figueiró (2009) apresenta a possibilidade de inserir resíduos sólidos durante a feitura dos tijolos, aumentando-se sua resistência.

\section{Metodologia}

O presente estudo é uma pesquisa bibliográfica com abordagem qualitativa, de modalidade teórica e com análise da bibliografia formal, discursiva e concludente. Para seu desenvolvimento foram pesquisados artigos e periódicos na área da engenharia, realizados em base de dados Scielo e Google acadêmico, além de outros sítios eletrônicos, tendo como descritor de busca as seguintes palavras chaves: alvenaria estrutural, elementos de vedação, construção civil. São apresentadas fotos da execução e acompanhamento de uma obra utilizando-se alvenaria estrutural, realizada na implantação de uma unidade de Pronto Atendimento da Prefeitura Municipal de Vassouras, estado do Rio de janeiro.

\section{Resultados e discussão}

$\mathrm{Na}$ alvenaria estrutural as paredes (ABNT 15961-1:2011) exercem a função de vedação e também constituem a estrutura resistente da edificação, podendo substituir pilares e vigas de concreto, para erguê-las necessita-se de blocos especiais, mais resistentes que as peças de vedação. Prudêncio Júnior et al. (2002) pontuam que eles podem ser de concreto, cerâmicos, sílico-calcários ou de concreto celular, sendo também possível utilizar-se tijolos maciços, assentados com juntas desencontradas e amarrados com ferragens. A utilização desse sistema permite a diminuição significativa no custo da obra, no entanto, deve-se destacar que os projetos mais detalhados devem ser elaborados considerando-se a modulação dos blocos e as características da solução.

O princípio básico do projeto de Alvenaria Estrutural é que as paredes devem ser portantes (ABCI, 1990), ou seja, capazes de resistir às solicitações impostas à estrutura, sendo, portanto, painéis laminares diferentes dos pórticos de barras das estruturas de concreto, que é formada por pilares e vigas, e também determinar os vãos modulares (portas e janelas) e todas as interferências na edificação (elevadores, caixas 'd'água, vagas de garagem). Dessa maneira, tudo deve ser calculado (FIGUEIRÓ, 2009) para a medida modular da alvenaria, distribuindo as cargas, diferente dos pilares de concreto (RICHTER, 2007).

Antes de iniciar a obra em alvenaria estrutural é 
necessário elaborar o projeto arquitetônico conforme apontam Tauil \& Nese (2010), pois a partir dele são feitas definições tais como: disposição e dimensão dos ambientes, aberturas de vãos, previsão de instalação de equipamentos e tipo de cobertura a ser utilizada. Ramalho \& Corrêa (2003) ressaltam que tudo deverá ser analisado dentro da normalização, custos, durabilidade, manutenção e disponibilidade dos materiais. O projeto arquitetônico é a base para o procedimento construtivo, se ele não for elaborado, ou se o for feito de maneira inadequada, poderá comprometer toda a produtividade e qualidade do empreendimento.

Devido à limitação da arquitetura na alvenaria estrutural, esse sistema construtivo não é considerado adequado para utilização de vãos grandes (por exemplo, para edifícios comerciais ou residenciais de alto padrão), por isso normalmente é utilizada em empreendimentos residenciais de padrão médio ou baixo, onde os ambientes são relativamente pequenos.

De acordo com Figueiró (2009), pode-se considerar como complementares todos os outros projetos de uma edificação, divididos em: estrutural e instalações. O Projeto Complementar Estrutural trata da mensuração e detalhamento da estrutura que sustentará a construção, sendo, portanto, responsável pela segurança do edifício, compreendendo a fundação e superestrutura. Já o Projeto Complementar de Instalações volta-se para inúmeros itens, onde pode-se destacar: elétrico, telefônicos, hidráulico, sanitário, prevenção e combate a incêndio, entre outros.

Segundo Duarte (1999), quando é feita a escolha de alvenaria estrutural, deve-se presumir a necessidade de integração de todos os projetos arquitetônicos.
Significa dizer que deve ser estudada com antecedência todas as aberturas de passagens para tubulações, elevatórias e escadas. Até porque as paredes de alvenaria estrutural não podem ser cortadas horizontalmente ou de forma inclinada, pois existe a necessidade de todas as tubulações, como hidráulica, por exemplo, estarem distribuídas na laje descendo ou subindo com dutos na vertical até os pontos de utilização.

A obra compreende a implantação de uma Unidade de Pronto Atendimento (UPA) da Prefeitura Municipal de Vassouras, estado do Rio de Janeiro, situada na Rua Marechal Paulo Torres, número 477, conforme indicado na placa de identificação posicionada na fachada da obra como mostra a figura 1. Na figura 2 é mostrado o assentamento da primeira fiada, onde a colocação dos blocos deve respeitar os limites da arquitetura, para que não haja quebra destes, uma vez que são considerados elementos estruturais e não apenas vedação.

A figura 3 mostra a primeira fiada já executada, onde se observa a verificação do esquadro, o preenchimento dos furos, colocação de grampos e tomando os devidos cuidados quanto às amarrações previstas em projeto.

Para ligar os blocos, utiliza-se argamassa, quem além de promover a referida ligação, possui a finalidade de tornar mais uniforme os apoios entre os mesmos, conforme a figura 4 mostra.

As vergas e contravergas em sistemas de alvenaria estrutural são feitas por meio de blocos estruturais do tipo canaleta onde são posicionadas as armações e o próprio bloco servirá de caixaria, conforme indicado na figura 5.

Figura 1. Placa de identificação da obra da UPA Vassouras/RJ.

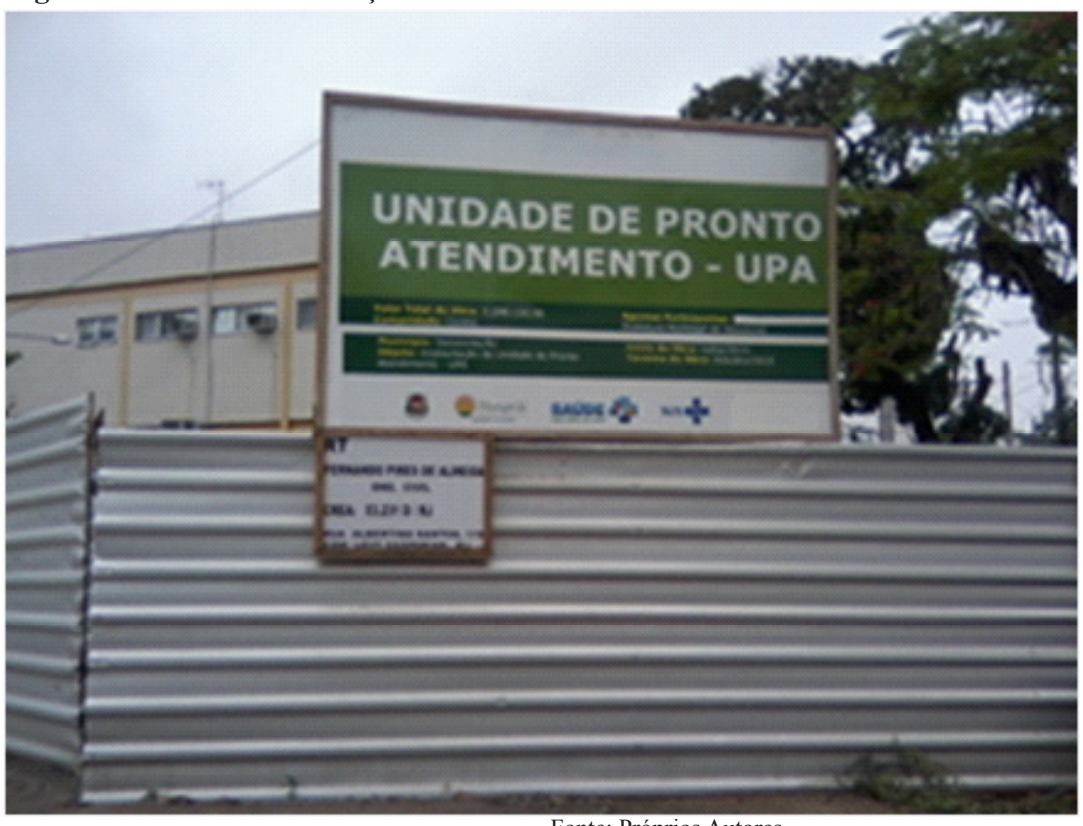

Fonte: Próprios Autores. 
Figura 2. Execução da obra com alvenaria estrutural: Marcação da primeira fiada.

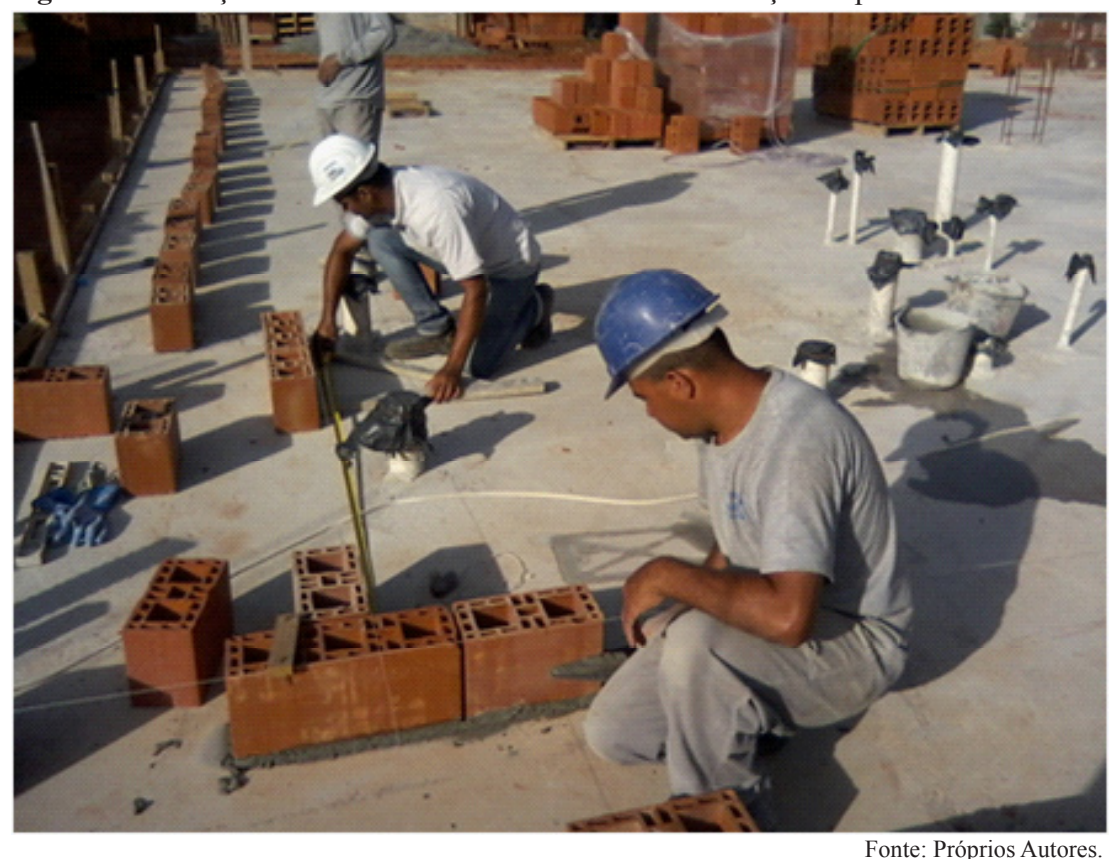

Figura 3. Execução da obra com alvenaria estrutural: Execução da primeira e segunda fiada.

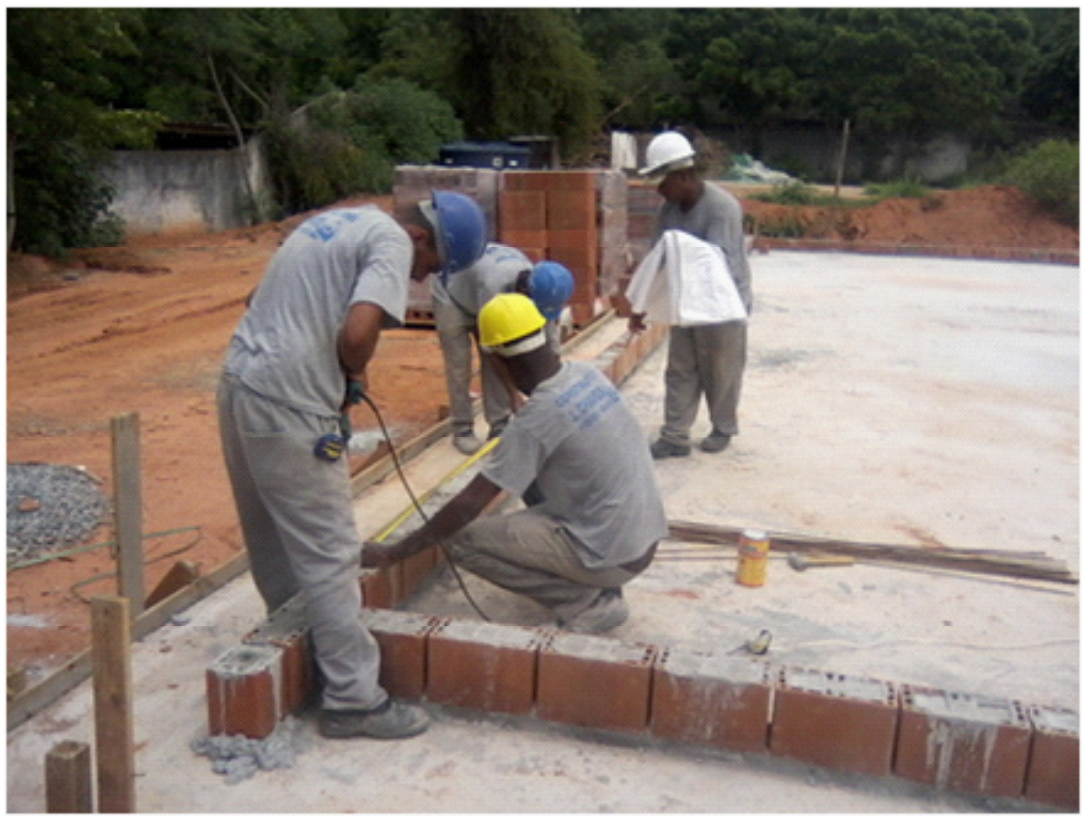

Fonte: Próprios Autores. 
Figura 4. Execução da obra com alvenaria estrutural: Utilização da bisnaga para aplicação da argamassa para assentamento dos blocos estruturais cerâmicos.

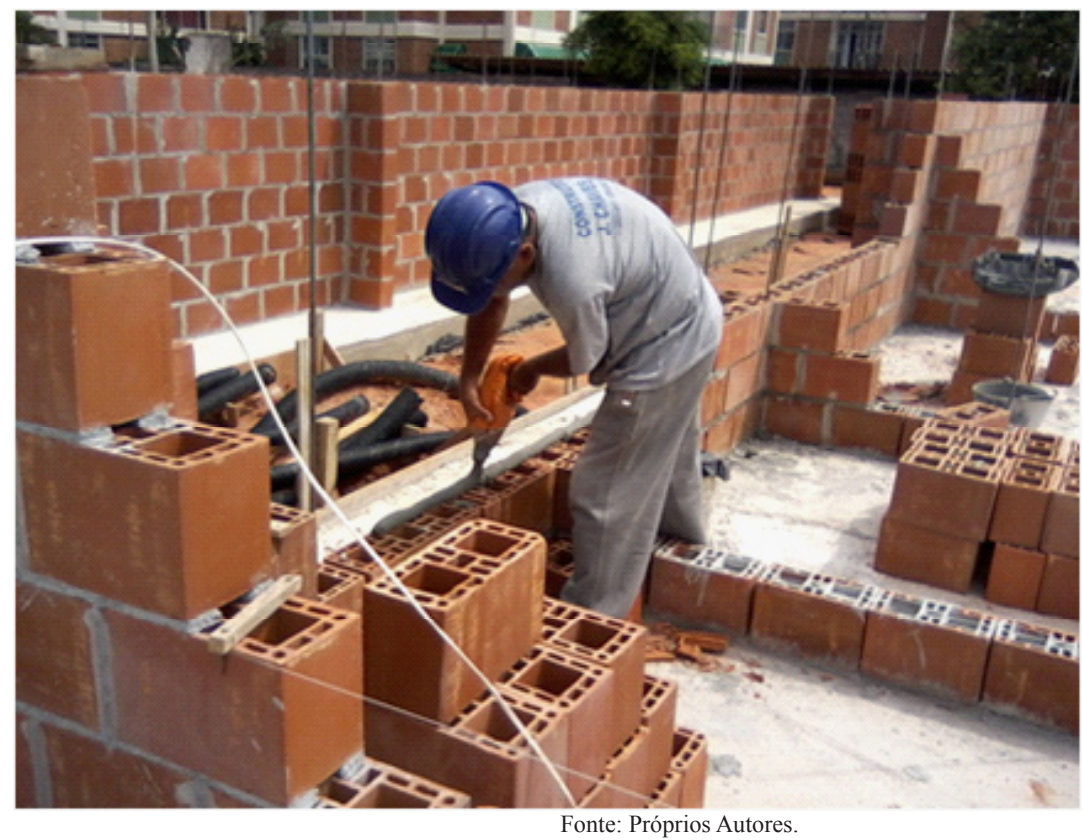

Figura 5. Execução da obra com alvenaria estrutural: Assentamento dos blocos estruturais cerâmicos e confecção da verga para reforço estrutural com bloco canaleta U.

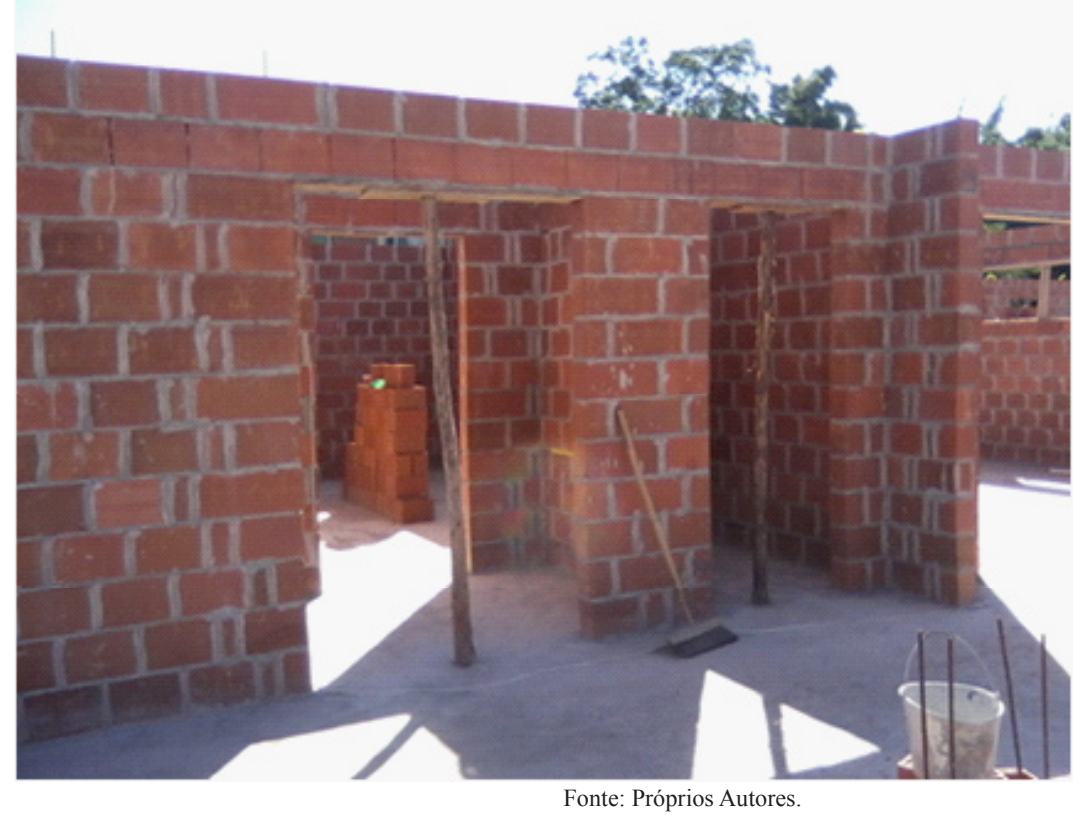

\section{Considerações Finais}

Observa-se na literatura consultada que os termos mais ligados à Alvenaria Estrutural são a racionalização e industrialização. Estes termos traduzem o ideário deste sistema que possibilita à construção civil os conceitos de linha de produção, de planejamento detalhado da construção, do não desperdício de tempo e material e do aumento da produção com redução de mão de obra e a padronização no método construtivo.
Apesar deste trabalho não ter abordado a respeito das limitações, o sistema construtivo em Alvenaria Estrutural, observou-se na pesquisa efetuada que como os demais sistemas, apresenta limitações que devem ser observadas com bastante atenção, para que se tenha um resultado satisfatório, tanto no que diz respeito à segurança e aos custos, quanto no que se refere ao produto final.

Outro dado que a pesquisa aponta é que nos projetos de Alvenaria Estrutural é fundamental que 
ocorra uma interação entre todos os participantes das equipes profissionais envolvidas, desde a etapa de concepção do projeto até a fase construtiva da edificação, pois o resultado final será baseado nessa interrelação.

No tocante à economia verificou-se que o sistema construtivo com blocos estruturais de concreto é uma resposta ágil às demandas habitacionais do país, uma vez que evita o desperdício e procura reduzir o tempo de execução. Reduzindo a geração de resíduos na fase de construção, economizando os materiais utilizados.

Acredita-se que novos estudos devam ser desenvolvidos, pois apesar do conhecimento técnico a respeito de construções de Alvenaria Estrutural estar sendo desenvolvido nas últimas décadas no Brasil, essa técnica construtiva parece não ter ainda uma significativa absorção pelas grandes construtoras.

\section{Referências}

ABCI. (1990). Manual técnico de alvenaria, Projeto/PW editores, Associação Brasileira da Construção Industrializada. Editor: Vicente Wissenbach. Coordenação Geral: Carlos Alberto Tauil.

ABNT NBR 15961-1. (2011). Alvenaria Estrutural- Blocos de concreto. Parte 1: Projeto.

APP (2010). Conceito de Alvenaria Estrutural pode racionalizar custos de construção. http://www.em.com.br/app/noticia/economia/2010/12/02/ internas economia,195871/conceito-de-alvenaria-estrutural-poderacionalizar-custos-de-construcao. Acesso em: 21 de agosto de 2015.

Banco de Obras (2013). Sistemas Construtivos: Alvenaria Estrutural. http:// www.comunidadedaconstrucao.com.br/banco-obras/1/alvenaria-estrutural/. Acesso em 22 de agosto de 2015.

Campos, I.M. (2012) O que é alvenaria estrutural?http://www. forumdaconstrucao.com.br/conteudo.php? $\mathrm{a}=7 \& \mathrm{Cod}=40$. Acesso em $21 \mathrm{de}$ agosto de 2015 .

Cavalheiro, O. P. (2009). Alvenaria Estrutural: Tão antiga e tão atual. Santa Maria. Silva, A.S. A Evolução dos Edifícios em Alvenaria Auto-Portante. 14f. Seminário, Departamento de Estruturas e Fundação, Escola Politécnica da Universidade de São Paulo.

Coêlho, R. S. A. (1998). Alvenaria Estrutural. São Luís: UEMA.

Duarte. R. B. (1999). Recomendações para o Projeto e Execução de Edifícios de Alvenaria Estrutural. Porto Alegre: ANICER.

Figueiró, W. O. (2009). Racionalização do Processo Construtivo de Edifícios em Alvenaria Estrutural. Monografia (Curso de Especialização em Construção Civil) - Departamento de Engenharia de Materiais e Construção, Universidade Federal de Minas Gerais, Belo Horizonte.

Hirt, E.; Marangoni, K. P. (2013). Estudos sobre a utilização de Alvenaria Estrutural em obras da Região Metropolitana de Curitiba. Trabalho de conclusão de curso apresentado à disciplina Trabalho Final de curso como requisito parcial à conclusão do Curso de Engenharia Civil, Setor de Tecnologia, Universidade Federal do Paraná. Curitiba.

Prudêncio Jr., L. R.; Oliveira, A. L.; Bedin, C. A. (2002). Alvenaria Estrutural de blocos de concreto. Florianópolis: Associação Brasileira de Cimento Portland.

Ramalho, M. A.; Corrêa, M. R. S. (2003). Projetos de edifícios de alvenaria estrutural. São Paulo: Editora Pini. 174 p.

Richter, C. (2007). Alvenaria Estrutural: processo construtivo racionalizado. São Leopoldo Universidade do Vale dos Sinos. Apostila do Curso da Área de Ciências Exatas e Tecnológicas. www.ceramicapalmadeouro.co..br. Acesso em: 22 de agosto de 2015.
Santos, E. V. (2012). Alvenaria Estrutural: Características e especificações, instruções de transporte, estocagem e utilização. Ijuí, RS: Cisbra Blocos.

Silva, A. M.; Costa, C. G. (2007). Alvenaria Estrutural com Bloco Cerâmico. Trabalho de Conclusão de Curso (Graduação em Engenharia Civil), Curso de Engenharia Civil, Universidade do Sul de Santa Catarina, Tubarão.

Tauil, C. A.; Nese, F. J. M. (2010). Alvenaria Estrutural. São Paulo: PINI. 